\title{
Assessing Online Asynchronous Communication Strategies Designed to Enhance Large Student Cohort Engagement and Foster a Community of Learning
}

\author{
Paul G Kebble \\ Correspondence: Paul G Kebble, Faculty of Education, University of Tasmania, Australia.
}

\author{
Received: June 15, 2017 \\ Accepted: July 3, $2017 \quad$ Online Published: July 13, 2017 \\ doi:10.11114/jets.v5i8.2539 \\ URL: https://doi.org/10.11114/jets.v5i8.2539
}

\begin{abstract}
With the increasing diversity of pedagogic models of delivery in higher education, universities are continually exploring practises of learning and teaching designed to enhance student experience and retention. The number of courses provided online continues to grow through, among other reasons, an escalation of higher education (HE) students requiring flexible approaches to learning and learner engagement. However, HE Students participating in online courses can experience a sense of physical isolation which, if allowed to escalate, can lead to reduced performance and potential withdrawal from courses. Creating an online learning environment that fosters a sense of connection and assimilation should enhance an individual's learning experience and engagement. This enquiry, conducted through a two-cycle participatory action research approach, was designed to explore possible strategies to enhance learner engagement. Elaborations introduced in cycle two, and the construct of recommendations, were based upon the analysis of data collected through online interactions between students and lecturer, appraisal of online student communications, and the utilisation of an online questionnaire. Participants were $2^{\text {nd }}$ year undergraduate Bachelor of Education students following a Design and Technology in Education course, with cohorts of 131 and 124 respectively. The research process included assessing the effectiveness of weekly newsletters and group discussion board summaries utilising student quotes, along with supporting practises, for promoting a sense of inclusion and improving interactions within online learning communities. The research concludes by providing a list of suggested strategies shown through this research to have enhanced large student cohort engagement and foster a community of learning and learners having shared values and aspirations, and willing to learn through engagement with others.
\end{abstract}

Keywords: discussion boards, asynchronous communication, large student cohort, community of learning

\section{Introduction}

Those involved in Higher education are increasingly engaged in learning and teaching online, with the focus on the quality provision of online pedagogy where appropriate knowledge is communicated, and learning is stimulated through the design of inspired interactions with provided materials, with peers and with the lecturer. Online HE learners, although often studying in physical isolation, are invariably expected to function within the university's digital learning management system (LMS). Palloff \& Pratt (2007) explain that learners engaged online face the possibility of a sense of loss, "loss of contact, loss of connection, and a resultant sense of isolation" (P. 31). The development of online learning and teaching strategies that adopt and sustain communities of learning, and hence inclusion, are therefore essential to student participation, performance and retention. And although there has been a "quantum leap" in the quality of online learning and delivery over the past 15 years (Salmon, 2013, p. xv)), creating and supporting an online community of learners is paramount for valuable learning and teaching to occur. Palloff \& Pratt (2007) clarify "the key to successful online learning is the formation of an effective learning community as the vehicle through which learning occurs online", and continue "the formation of a learning community through which knowledge is imparted and meaning is co-created sets the stage for successful learning outcomes" (P. 4). Conrad \& Donaldson (2004) state "Activities that require student interaction and encourage a sharing of ideas promote a deeper level of thought" and continue by stating "In an engaged learning environment, each learner's actions contribute not only to individual knowledge but to overall community knowledge development as well" (p. 5).

Valuable and valued communications between all learning and teaching participants would appear to be vital for quality learning to occur within an online environment. Available avenues for online communications are limited to what is 
provided within the university's LMS and occasionally augmented through the use of external social media sites, however, this research focuses on the most commonly used LMS communication tools, (Schrire, 2006; De Wever et al., 2006) discussion boards and email. In the researcher's experience, discussion board usage receives a broad range of support from lecturers, with advocates extolling its interactional qualities, and detractors complaining of limited student involvement and collaborative value. Online discussions can provide certain advantages (De Wever et al., 2006; Huang \& Hsiao, 2012) in that "students get more opportunities to interact with each other and students have more time to reflect, think, and search for extra information before contributing to the discussion" (De Wever et al, 2006, p. 7). The discussion board environment, if successfully implemented, is able to Bridge the gap between face to face and online learning, according to Darabi et al (2011), and therefore enhance connectedness between all involved.

Connectedness between all course participants, including the lecturer's involvement, appears to provide strong learning and engagement motivation, the opposite can also be argued. Online students complain that limited involvement by lecturers results in a feeling of neglect, with adverse consequences (Song et al., 2004). Timely and consistent lecturer participation will augment the provided materials and stimulate students to engage with course materials and communication channels regularly. Hill's (2002) research suggests implementing strategies such as discussion board involvement can augment the success of the online learning process, but continues by proposing that a regular schedule needs to be established for engaging in the dialogue that occurs in an online context. Song et al. (2004) concur that time management is of paramount importance and regularised lecturer interactions will support and enhance students' timely involvement throughout an online course of learning. Planning and actioning engagement, then, is crucial to the quality of online learning and Clark \& Mayer (2008) concluded, through a comprehensive analysis of research conducted into online teaching a learning, "students in well designed and well-implemented online courses learned significantly more, and more effectively, than those in online courses where teaching and learning activities were not carefully planned"(p. 13).

While Davidson-Shivers, Tanner \& Muilenburg (2000) state in "asynchronous discussions, students had more time to think about their responses and that the increased thinking time improved the depth and quality of responses. Biggs and Tang (2007) also discuss the value of students having time to be able to respond in an informed way, however, they also warn "A disadvantage of asynchronous online discussion is that that those who place their views first on online discussion can frustrate others who wanted to make the same points" (p. 71). Through an extensive quantitative study, Krentler \& Willis-Flurry (2005) were able to show that regular discussion board involvement had highly positive results, and found "Students who participated in class discussion online $76 \%-100 \%$ of the time earned a significantly higher course grade point average $(\mathrm{GPA}=2.69)$ than all other students" (p. 318).

Palloff and Pratt (2007) describe the functionality of a discussion board environment as where "a network of interactions between the instructor and the other participants is formed, through which the process of knowledge acquisition is collaboratively created" (p. 5) and continue by stating "The most powerful experiences are those in which interaction occurs throughout the group instead of between one participant and the facilitator within a group setting" (p. 21). In Rennie and Morrison's opinion (2013), the discussion board, amongst other forms of online communication "needs to be carefully balanced as part of a symbiotic learning system that brings benefits to the learners (p. 60)". Harman and Koohang, when discussing e-learning tools, report $(2005$, p. 67) "discussion boards represent the primordial mi-lieu in which e-learning and communities of learning emerged and that discussion boards remain an integral tool for e-learning" while Bender states "the energy of the online course occurs on the discussion boards" (2003, p. 37). According to the Hanover Research Council review (2009) online discussion forums "are one of the best ways to facilitate interaction and learning in the online classroom" (p. 15), partly attributed to their ability to promote constructivist, critical and higher-order thinking. Conrad and Donaldson (2004) explain that asynchronous activities, such as discussion boards, "allow each voice to be heard, whether in a small or large group, helping learners feel that they are part of a learning community and increasing their motivation to interact" (p. 22). Qualitative research conducted by Kupczynski et al (2012) also showed a cooperative system of learning through engagement with peers in the discussion board environment enhanced multiple elements of learning and teaching, such as: brain-storming, collaboration, communication, engagement, equal opportunity, feedback, independence, participation, and overall quality of learning.

Although it is generally agreed within the literature that discussion boards are a fundamental requirement in online learning and teaching (Price \& Kirkwood, 2013), the length of a post is a subject of conjecture. Experience has shown that at postgraduate level, a longer post of over 200 words is occasionally acceptable, whereas this is not the case with undergraduate students. Bender (2003, p. 9) warns "student postings of excessive length created disincentives for discussion" and I have often witnessed exactly this scenario where a student has provided an extended post, without reply. Providing clear requirements for posts prior to discussion board engagement would appear to be appropriate, although I suggest this can be augmented by providing an exemplar of a quality thread which includes all elements discussed within the requirements.

This research, through a participatory action research (AR) process, wishes to assess and improve the online learning 
and teaching techniques employed within the asynchronous communication avenues provided within the university's LMS. Improvements will be informed through a process of analysing participant feedback, practitioner reflections and relevant literature. This limited research project will conclude with the production of a set of recommended practices that can be employed, with further refinement encouraged.

\section{Background to Research}

This research emanated from feedback focused on the previous iteration of the discussion board and communication systems received from participating students in a $2^{\text {nd }}$ year undergraduate education elective course in Primary Technology and Design Education. This elective consistently recruited between 100 and 140 students and was delivered both on campus and online, with approximately $15 \%$ of the cohort attending lectures and tutorials on campus, and a further small group of Indigenous teacher trainees learning at another campus. The inherited course online communications system included what was described through feedback as irregular emails from the lecturer and an assessed discussion board component, with received criticism focused on the lack of peer interaction, lecturer involvement and equitability of the assessment procedure. Discussion topics were presented within the online materials and numbered between three and eight per week. Students were encouraged to choose 2 topics per week, and were assessed on what was deemed by the lecturer as their 10 best posts. With the newly acquired responsibility of coordinating and delivering this course, I wished to enhance the quality of delivery and student experience through a systematised process of reflective practice. Initially utilising the initial feedback, my own previous experiences and current literature, I formulated a system of communications designed to address the described concerns. I was also cognisant of the need for a systematic approach to reflective practices that inform the development of pedagogical practices, and chose to engage in a two cycle action research process. Having attained the appropriate ethics clearances, I initiated the action research project.

\section{Action Research Design}

This research was designed as a two-cycle participatory AR project where the researcher critically examines their own pedagogic practice. Parsons and Brown (2002) have described AR in teaching as a methodology that provides teachers with a tool for attaining valid and useful data which can be used to develop effective pedagogical practices. Kemmis and McTaggart (2005) referred to this process as "classroom action research" and suggest "classroom action research typically involves the use of qualitative interpretive modes of inquiry and data collection by teachers with a view to teachers making judgements about how to improve their own practices." (p. 561). This research utilised the university student feedback system, direct communications between students and the lecturer, and a post-course online questionnaire. After the second action research cycle, the research used a short anonymous online questionnaire for data collection, with polar questions using 5 point Likert scales and space for extended responses. For data analysis, the researcher employed a simple mixed method approach, with 37 students provided a response to the questionnaires. The questionnaire is shown in appendix 1.

This research adopted the cyclical model of AR described by Kemmis and McTaggart (2005) and shown in Fig. 1 below. The researcher completed two cycled of AR, using information collected from each cycle to assess previous and inform future developments.

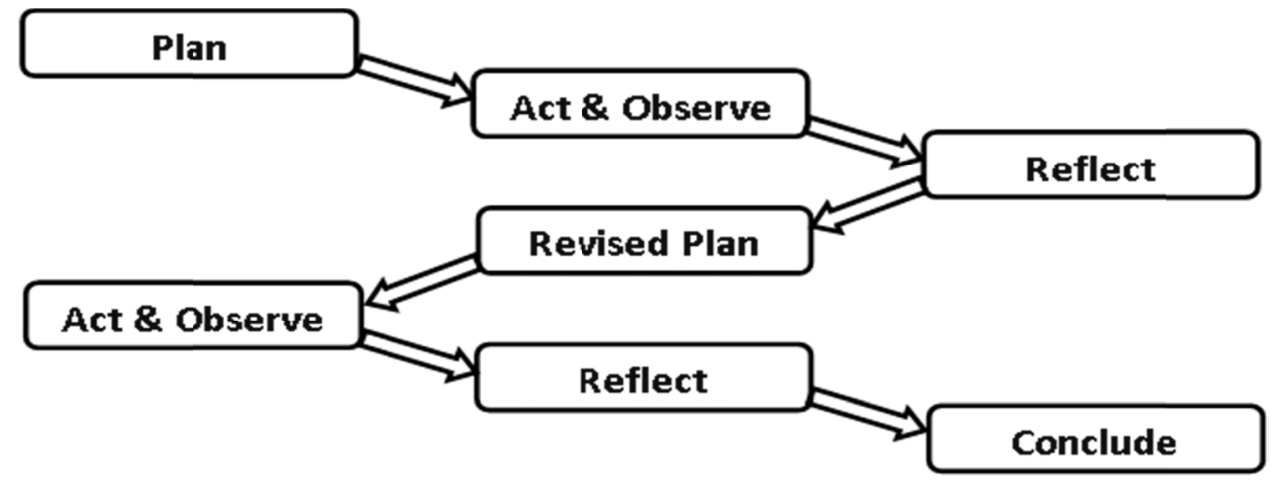

Figure 1. Action Research model utilised (adapted from Kemmis \& McTaggart, 2005)

\section{Action Research Cycle One}

Plan (1): Within the first AR cycle, the researcher wished to address the major concerns gleaned from engaging with previous student course feedback. These, along with the proposed plan of action, are shown in the table below: 
Table 1. AR $1^{\text {st }}$ Cycle Issues and associated plan of action

\begin{tabular}{lll}
\hline Issue & Plan \\
\hline 1) Online discussion group size too large & $\begin{array}{l}\text { divide the cohort into smaller discussion groups of approximately 20 students } \\
\text { limit topics to no more than four each week }\end{array}$ \\
2) Too many weekly discussion topics & $\begin{array}{l}\text { Provide a weekly email newsletter } \\
\text { 3) Lack of Communication from Course } \\
\text { lecturer }\end{array}$ & $\begin{array}{l}\text { Provide: 1) explanation of assessment requirements, 2) assessment criteria and } \\
\text { rubric }\end{array}$ \\
\hline
\end{tabular}

Act and Observe (1):

1) The cohort was 123 students altogether, with 16 attending regular on-campus lectures/tutorials, and a further 5 Indigenous students studying at another campus. I divided the cohort into 6 groups alphabetically, with approximately 20 students in each group. My observations showed that in each group approximately $40 \%$ of students provided regular (each week or two) posts, with another 30\% providing posts irregularly (every 3-4 weeks). The remainder either initiated or added to posts retrospectively (towards the end of the course), or not at all.

2) Usually, four discussion topics were presented within each week's course materials. Generally, all topics were engaged with, but invariably only two extensively.

3) Over the semester, I provided a weekly newsletter as an email discussing elements of the course, the assignments, reminders of deadlines, and encouraging online engagement. These were written in a professional manner but included humour and emoticons. I would receive a limited number of replies and would reply to these within two days. Overall, and on average, I would receive no more replies that $10 \%$ of the cohort each week, and occasionally three weeks out of twelve) none.

4) Although I received a number of emails asking me to clarify the assessment procedure and requirements, generally the cohort understood the assessment system. I received most enquiries asking whether 10 posts altogether was enough to satisfy assessment requirements, or whether students needed to enter into discussions every week.

\section{Reflections (1) and Revised Plan for Action Research Cycle 2:}

An online questionnaire was provided to the cohort asking for reflections and advice regarding course communications, course content, assessment, and learning organisation. A synthesis of the responses, along with a plan of action for cycle two is shown in the table below.

Table 2. AR cycle 1 reflections informing action plan

Reflection
1) Although students commented that the discussion grouping generally worked well, particularly as they felt a part of a learning community, they were concerned their grouping was limiting and did not allow for full-cohort inclusion.

2) Discussion topic number - how many?

3) Continuation of weekly newsletters

4) Assessment system and requirements - further definitions and descriptions.

5) Students throughout the course asked what a quality post looked like.

\section{Revised Plan}

To help alleviate this issue, I planned to provide a weekly discussion board summary and include direct student quotes that could be used to focus on the most relevant and pertinent issues from the week's topic and materials. I surmised by providing regular summaries of students' discussions utilising direct student quotes, the following would be achieved:

a) students are made aware that all online contributions are read

by the lecturer

b) salient concepts and ideas from the course content for that particular week can be highlighted through the discussion and related quotes

c) the diversity of ideas and contributions can be presented and commented upon by the lecturer

d) inclusivity and a sense of community can be promoted by affording a direct voice to students.

I would reduce the number of discussion topics provided to between two and four, but encourage students to create their own topic thread if they wished to raise a particular issue.

This, I believed, had been successful and I would maintain the system.

To enhance the provision of information pertaining to the assessment requirements, particularly what was construed as a quality thread and post, I would provide comprehensive and clear information answering the main issues that had be raised over the previous course to be offered in conjunction with the previously constructed information sheet.

I decided I would provide exemplars from the previous course, de-identified and with appropriate permissions. These were chosen to show how a quality thread might appear, and included a range of interesting, supportive, entertaining and academic posts of varying lengths. 
Act and Observe (2)

1) The writing of the discussion board summary occurred on the following Wednesday of each week's discussion. The process required deciding on which topic areas to focus, reading a wide variety of posts and selecting appropriate quotes, and constructing the text. This would take two to three hours and the summary would be emailed to all participants by the end of that day. As the weeks progressed, I kept a record of who I had quoted and endeavoured to include as many participants as I was able, and certainly the regular contributors. I received many positive emails, with those I quoted often commenting further on their quote, or reiterating their thoughts, in, I believe, recognition and appreciations of my inclusion. Below is an example of one summary provided at week three:

Table 3. Example of weekly discussion board summaries

This week's discussions were centred around the four topics below, with the vast majority of comments for (1) \& (2)

(1) Design \& Technology at school - was/is it a stand-alone subject?

(2) Is Design \& Technology a science subject?

(3) Similarities/differences between curricula

(4) Ethics and Design \& Technology

(1) Design \& Technology at school - was/is it a stand-alone subject?

Most feedback suggests that at High school Design \& Technology was a stand-alone subject, but not in primary schools. C*** (Gr2) discusses that "Thinking back to the days of primary school I don't believe Technology was a specific subject. Although I do remember once a week we were taken to the I.T. room to play on programs including KidPix and paint.

$\mathrm{B}^{* * *}$ (Gr3) attached a comprehensive 2 page document which discussed the cross-curricula nature of Design \& Technology when stating that: "Technologies and design rely on effective literacy and numeracy skills, as well as an understanding of history, geography, society and the environment"

$\mathrm{J}^{* * *}$ (Gr5) argues that D\&T is positioned as both when stating "it really does need to be a subject in it's own right, whilst still being intergrated into other subjects such as science, mathematics, art, etc"

$\mathrm{K}^{* * *}$ (Gr4) provided an insight into her son's schooling, and described "my son is in grade one this year and they have a subject called Investigative Learning, the children are able to investigate and work on a project that interest them such as looking up their favourite animal on the computer or making a back pack for a teddy after measuring its height and width." While J*** (Gr6) also discussed her my middle son's recent D\&T experience, who "partnered up and designed, made and appraised a moving vehicle. This lesson crossed over with math as they measured the distance each vehicle would travel and write about why they believe one travelled further than the other."

2) This balance appeared to work well, with students generally limiting their discussion to the provided topics, but with a limited number adding their own threads, often appreciated by others.

3) Newsletters were well received, as before. An example of a newsletter from week 4 is provided below

Table 4. Example of weekly newsletter

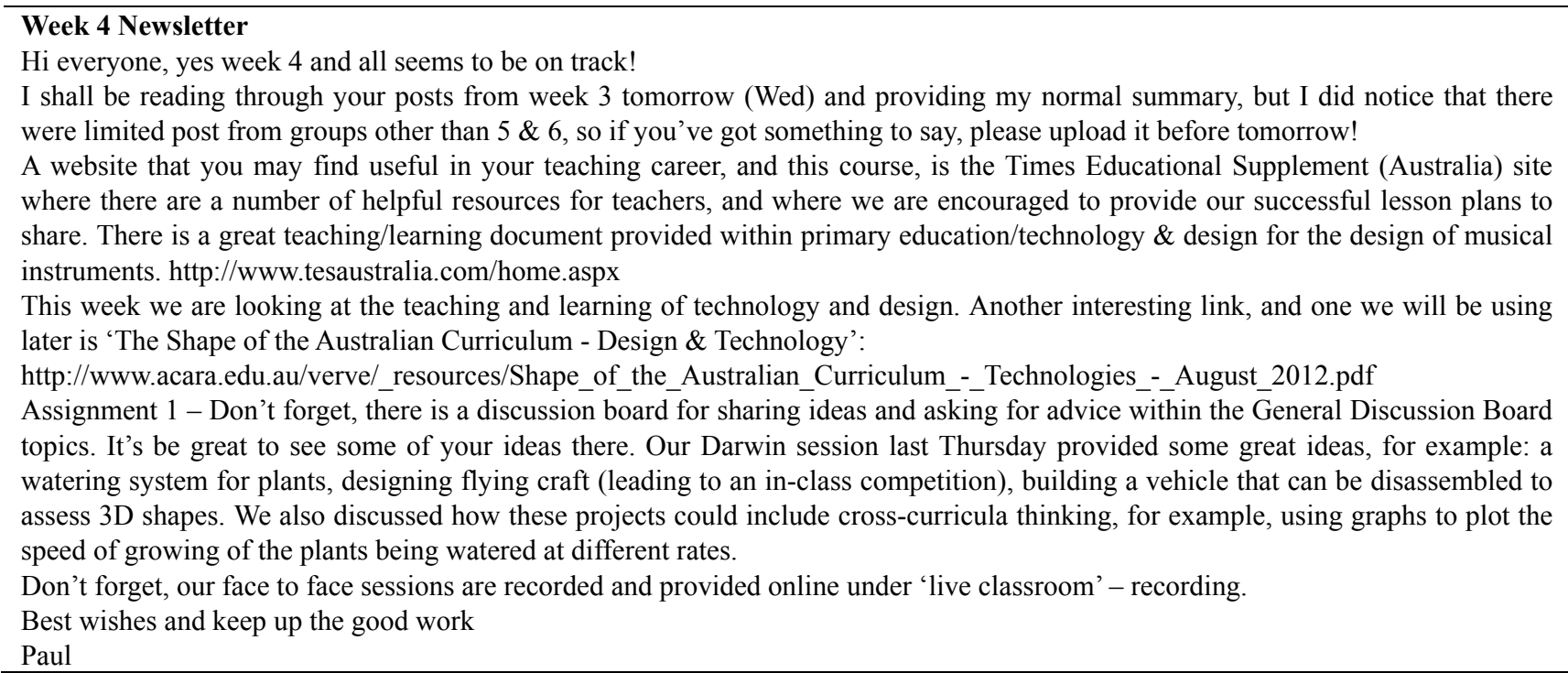

4) Although not totally negated, I received far fewer emails asking for further assessment clarification.

5) The exemplars were well engaged with and students commented very favourably both on their provision and on the quality and range of discussions. 


\section{Reflect (2) Informed by Student Feedback}

Student responses to the questionnaire showed a very positive response to the strategies introduced, clearly shown through the following data collected from Survey Monkey.

Table 5. Statistical analysis of questionnaire feedback

\section{Question:}

1) Did you read the emails that provided weekly course updates?

2) If Yes to (1) How useful did you find them: 36 on a scale of $1-5$ where 1 is not useful and 5 is very useful

3) Please respond to the following statements on a scale of 1 to 5 where $1=$ negative and 5 = very positive:

The weekly course updates ....

4) Did you read the emails that provided weekly discussion board summaries?

5) If Yes to (4) How useful did you find them: on a scale of $1-5$ where 1 is not useful and 5 is very useful

6) Please respond to the following statements on a scale of 1 to 5 where $1=$ negative and 5 = very positive:

The weekly discussion board summaries...

Replies Response

$37 \quad$ Yes $=36(97.3 \%)$

No $=1(2.7 \%)$

Not Useful $=0(0 \%)$

Somewhat useful $=1(2.78 \%)$

Quite useful = $4(11.11 \%)$

Useful $=10(27.78 \%)$

Very useful $=21(58.33 \%)$

36 ...provided suitable and appropriate information $=4.53$

...were interesting $=4.42$

...helped me to keep on track with course requirements and content $=$ 4.53

...were not especially useful $=1.77$

...provided encouragement to engage with the course $=4.50$

... were stimulating $=4.31$

Were enjoyable to read $=4.33$

$37 \quad$ Yes $=34(91.89 \%)$

No $=3(8.11 \%)$

$34 \quad$ Not Useful $=0(0 \%)$

Somewhat useful $=3(8.82 \%)$

Quite useful $=3(8.82 \%)$

Useful $=8(23.53 \%)$

Very useful $=20(58.82 \%)$

...provided suitable and appropriate information $=4.38$

...were interesting to read $=4.32$

...were not especially useful $=1.61$

...provided me with a broad overview related to the week's topics $=$ 4.49

$\ldots$ were stimulating $=4.24$

...were enjoyable to read $=4.33$

...were too long $=1.91$

Table 6. Selected comments from questionnaire

Some responses to: please comment further on the weekly course updates...

- Informative and supportive

- Appreciated the enthusiasm and consistency of communication

- Useful to stay on track especially when I was doing other units simultaneously

- A good motivator to keep on track and also it showed that the lecturer was interested in his students and keeping in touch with them

- I liked the weekly updates because it kept me on track and I enjoyed reading comments from other students

- $\quad$ showed keen interest by the lecturer

- $\quad$ They were a help when you were not able to make it to class. And wanted to catch up on what had happen. As reading is not one of my strong side but this made it easier for me. More helpful then some other classes

- These help you to feel supported and on track and in communication with the lecturer - less isolated than other units

Some responses to: please comment further on the weekly discussion board summaries...

- Awesome, I was so impressed with the weekly summaries it made me feel connected to the groups without having to read posts from every student but I still got the information

- Inclusive - I thought it was a great way to find out what people in other discussion were thinking/saying. I loved this touch

- Helpful

- engaging, especially as I was an external student, gave me community feeling looking at others point of view, sharing knowledge and experiences $=$ informative and helpful

- They inspired me to contribute to the best of my ability in the hope of my comments being included in the weekly summary. It was such a thrill when my answers or comments were mentioned, I felt part of the group and that the teacher was interested in our weekly progress or lack of

- I don't like the discussion boards, and had I not been overwhelmed with other reading, I would have used these as a summary tool of what was written on the discussion boards. I had a squiz at one once and felt it was a little long, so didn't bother reading it

- $\quad$ please continue to use these summaries. It provides a basis of the students understanding and encourages further discussion about the questions. fabulous idea!

- I was pleased to see lecturer was actually reading posted comments (for some units I've had my doubts) 


\section{Discussion and Recommendations}

Lecturers discuss concerns directed at the overuse of the email system, complaining of multiple personal emails from students asking similar questions. Experiences gained through this action research suggest this issue can be seriously moderated by providing clear and concise information at the outset of the course and by providing regular newsletter emails. I received significantly fewer direct emails, particularly over the second iteration of the course, and in some cases I received no emails during the week.

A further described benefit of these strategies was that the emailed newsletters and weekly discussion board summaries stimulated students to keep 'on track' with the course.

Finally, through this participatory action research process, the following list of recommendations have been developed designed to inform learning and teaching practices when working with students online, and particularly with larger cohorts.

Below is the list offered for peer consideration, with feedback welcomed.

\section{Recommendations for online discussion board engagement strategies informed through the described reflective practices}

1) Divide large cohorts into smaller online groups of no more than twenty students.

2) Provide clear descriptors of what constitutes acceptable discussion board contributions.

3) Describe acceptable language use as both professional and academic through an affable and respectful tone.

4) Provide an exemplar of quality discussions.

5) Provide a rationale for the expectations of online communications and assessment.

6) Explain it is acceptable to provide a single sentence in response, although extensive posts are not easily engaged with. Setting a limit of 200 words as a maximum may be appropriate.

7) Discussion board contribution to be assessed, with a recommended $20 \%-30 \%$ weighting.

8) Provide clearly defined assessment rubric and criteria.

9) Setting a minimum number of contributions (in my case, 10), with an explanation that the LMS system is able to collate an individual's contributions. This minimum requirement requires further investigation, and may not be suitable in certain settings, particularly where lecturers require weekly contributions.

10) All students encouraged to share resources, links to relevant materials, and provide references and URLs to valid sources of information presented within posts.

11) Provide weekly newsletters discussing issues and topics to be presented during the week, along with any other topics deemed interesting or important.

12) Provide weekly summaries of discussions gleaned from an overview of all group discussions. Use student quotes from these discussions, particularly to provide focus on main issues raised or planned.

\section{References}

Bender, T. (2003). Discussion-Based Online Teaching to Enhance Student Learning: Theory, Practice, and Assessment. Sterling, Virginia: Stylus Publishing, LLC.

Biggs, J., \& Tang, C. (2007). Teaching for Quality Learning at University. Cambridge, England: Open University Press \& McGraw-Hill Education.

Clark, C. C., \& Mayer, R. E. (2008). e-Learning and the Science of Instruction: Proven Guidelines for Consumers and Designers of Multimedia Learning. San Francisco, CA: John Wiley \& Sons, Inc.

Conrad, R. M., \& Donaldson, J. A. (2004) Engaging the Online Learner' Activities and Resources for Creative Instruction. San Francisco, CA: Jossey-Bass.

Darabi, A., Arrastia, M. C., Nelson, D. W., Cornille, T., \& Liang, X. (2011). Cognitive presence in asynchronous online learning: a comparison of four discussion strategies. Journal of Computer Assisted Learning, 27(3), 216-227. https://doi.org/10.1111/j.1365-2729.2010.00392.x

Davidson-Shivers, G., Tanner, E., \& Muilenburg, L. (2000). Online discussion: How do students participate? Paper presented at the annual meeting of the American Educational Research Association, New Orleans, LA.

De Wever, B., Schellens, T., Valcke, M., \& Van Keer, H. (2006). Content analysis schemes to analyze transcripts of online asynchronous discussion groups: A review. Computers and Education, 46, 6-28. 
https://doi.org/10.1016/j.compedu.2005.04.005

Harman, K., \& Koohang, A. (2005). Discussion board: A learning object. Interdisciplinary Journal of Knowledge and Learning Objects, 1, 22-31.

Hill, J. R. (2002). Overcoming obstacles and creating connections: Community building in Web-based learning environments. Journal of Computing in Higher Education, 14(1), 67-86. https://doi.org/10.1007/BF02940951

Huang, X. S., \& Hsiao, E. (2012). Synchronous and asynchronous communication in an online environment: Faculty Experiences and Perceptions. Quarterly Review of Distance Education; Charlotte 13.1, 15-30, 49-50.

Kemmis, S., \& McTaggart, R. (2005). Participatory action research: Communicative action and the public sphere. In N. Denzin and Y. Lincoln (Eds.) Handbook of Qualitative Research (3rd Ed.) (pp. 559-604). Thousand Oaks CA: Sage.

Krentler, K. A., \& Willis-Flurry, L. A. (2005). Does technology enhance actual student learning? The case of online discussion boards. Journal of Education for Business, 80(6), 316-321. https://doi.org/10.3200/JOEB.80.6.316-321

Kupczynski, L., Mundy, M., Goswami, J., \& Meling, V. (2012). Co-operative learning in distance learning: A mixed methods study. International Journal of Instruction, 5(2), 81-90.

Palloff, R. M., Pratt, K., \& Palloff, R. M. (2007). Building online learning communities: effective strategies for the virtual classroom. San Francisco, CA: Jossey-Bass.

Parsons, R. D., \& Brown, K. S. (2002). Teacher as reflective practitioner and action researcher. Belmont, CA: Wadsworth/Thomson Learning.

Petrides, L. A. (2002). Web-based technologies for distributed (or distance) learning: Creating learning-centered educational experiences in the higher education classroom. International Journal of Instructional Media, 29(1), $69-77$.

Price, L., \& Kirkwood, A. (2013). Using technology for teaching and learning in higher education: a critical review of the role of evidence in informing practice. Higher Education Research and Development. Retrieved from: http://oro.open.ac.uk/34804/

Rennie, F., \& Morrison, T. (2014). E-Learning and Social Networking Handbook: Resources for Higher Education. Studies in Continuing Education, 36(3). http://dx.doi.org/10.1080/0158037X.2014.952948

Salmon, G. (2013). E-tivities: The key to active online learning. Routledge.

Schrire, (2006). Knowledge Building in Asynchronous Discussion Groups: Going Beyond Quantitative Analysis. Computers \& Education, 46, 49-70. https://doi.org/10.1016/j.compedu.2005.04.006

Song, L., Singleton, E. S., Hill, J. R., \& Koh, M. H. (2004). Improving online learning: Student perceptions of useful and challenging characteristics. Internet and Higher Education, 7, 59-70. https://doi.org/10.1016/j.iheduc.2003.11.003

Tallent-Runnels, M. K., Thomas, J. A., Lan, W. Y., Cooper, S., Ahern, T. C., Shaw, S. M., \& Liu, X. (2006). Teaching Courses Online. A Review of the Research, 76(1), 93-135.

The Hanover Research Council review (2009). Best Practices in Online Teaching Strategies. Retrieved from http://www.uwec.edu/AcadAff/resources/edtech/upload/Best-Practices-in-Online-Teaching-Strategies-Membership .pdf 
Appendix 1. Questionnaire for Research into the provision of weekly course updates and discussion board summaries.

Questionnaire for Research into the provision of weekly course updates and discussion board summaries

Over the $* * * *$ course, weekly course updates and discussion board summaries were provided via email. This questionnaire investigates your involvement with and thoughts about this procedure.

The survey is anonymous and no question asks for any personal information.

The survey is also completely voluntary and you are under no obligation to be involved.

The first question requires you to verify that you understand that this is an anonymous and optional survey and that you are willing to be involved.

Thank you very much for your participation.

I understand that this is an anonymous and optional survey and that I am willing to be involved: $\mathrm{Y} / \mathrm{N}$

1) Did you read the emails that provided weekly course updates: $y / n$

- If yes: How useful did you find them, on a scale of 1 - 5? Not at all useful ----very useful

- If no, why?

2) Did you read the emails that provided weekly discussion board summaries: $y / n$

- If yes: How useful did you find them, on a scale of 1 - 5? Not at all useful ----very useful

- If no, why?

3) Please respond to the following questions on a scale of 1 - 5? Not at all useful ----very useful

a) The weekly course updates:

- $\quad$ provided suitable and appropriate information

- were interesting

- $\quad$ helped me to keep on track with the course requirements and content

- $\quad$ were not especially useful

- provided encouragement to engage with the course

- were stimulating

- were enjoyable to read

What other words or phrases would you use?

b) The weekly discussion board summaries:

- $\quad$ provided suitable and appropriate information

- were interesting to read

- $\quad$ were not especially useful

- $\quad$ provided me with a broad overview related to the week's topics

- were stimulating

- were enjoyable to read

- were too long

What other words or phrases would you use?

4. Please could you spend a couple of minutes commenting on each of the procedures

- Weekly course updates

- Discussion board summaries

Thank you for your time and effort in completing this, it is much appreciated!

\section{Copyrights}

Copyright for this article is retained by the author(s), with first publication rights granted to the journal.

This is an open-access article distributed under the terms and conditions of the Creative Commons Attribution license which permits unrestricted use, distribution, and reproduction in any medium, provided the original work is properly cited. 